\section{Is it time for a national screening programme for sight-threatening diabetic retinopathy?}

Few management strategies in medicine have more supporting evidence than that of laser photocoagulation for sight-threatening diabetic retinopathy ${ }^{1,2}$ and maculopathy. ${ }^{3,4}$ The Diabetic Retinopathy Study showed that after panretinal photocoagulation (PRP) for proliferative retinopathy with high-risk characteristics, there was a relative risk reduction (RRR) of $51.5 \%$ and a number needed to treat (NNT) of 14.3 (95\% confidence interval (CI) 9.9-25.8). ${ }^{2}$ In the Early Treatment Diabetic Retinopathy Study focal argon laser reduced moderate visual loss in clinically significant macular oedema (CSMO) at 3 years with a RRR of $50 \%$ and a NNT of 8.3 (95\% CI 6.6-11.4). ${ }^{3}$ The results from Olk's randomised controlled trial of 'modified grid' in eyes with diffuse maculopathy with or without CSMO at 2 years showed an even more impressive RRR of $78 \%$ with a NNT of 3.0 (95\% CI 2.0-5.6). ${ }^{4}$ The early stages of disease are asymptomatic and the benefits of laser photocoagulation are lost later in the disease, ${ }^{5,6}$ emphasising the importance of early detection and treatment.

Sight-threatening diabetic eye disease is generally considered to be a good example of a disease in which screening is justified. It remains the commonest cause in the UK of blind registration in the population between the ages of 16 and 64 years $(11.9 \%)$ and the third commonest in all age groups $(3.4 \%) .^{7}$ Modelling techniques have been used by various authors to estimate the probable yield from screening and its expected impact in a diabetic population, and have provided strong supporting evidence that screening and early treatment can prevent substantial disability and achieve large economic benefit. ${ }^{8-11}$ Screening for diabetic retinopathy has been heralded as the method by which targets such as the St Vincent Declaration may be achieved. ${ }^{12}$

It is no surprise, therefore, that there is widespread agreement that screening for sightthreatening diabetic eye disease could make an important contribution to preservation of visual function, and the development of a national screening initiative is now being considered.
However, there remain a number of unanswered questions and important areas of missing or inadequate data.

There is at present no consensus on the optimal method of screening. Direct ophthalmoscopy and screening by untrained health professionals have both been discredited, although many health authorities remain mistakenly of the view that the 'screening programmes' they have adopted are effective. Two options are emerging as the main ways forward: photographic programmes with 35 $\mathrm{mm}$ or digital image recording, grading with internal and external audit and dedicated assessment clinics; and slit-lamp biomicroscopy-based programmes performed by optometrists with full and continuing accreditation and audit. The former has shown satisfactory sensitivity and specificity ${ }^{13}$ but meaningful effectiveness data are not available on the latter. Both options are primary care based, which is a prerequisite to effective compliance and allows dedicated assessment clinics to avoid overloading the hospital eye service. Much-needed cost-effectiveness data on these options when they become available will help inform purchasers. National screening, if established in the UK, will probably commence as a 'mixed economy' while the impact of new technologies is evaluated and issues in training are clarified.

How to monitor the impact and outcome of screening remains problematic. There is as yet no published evidence that screening for diabetic retinopathy in any area of the UK has resulted in a decrease in registrable blindness. The well-recognised under-registration makes such research difficult, ${ }^{14}$ as does the inability to generate data by postcode. In addition not all severe sight loss in diabetic patients is due to retinopathy. Ronald Klein reported that more than $80 \%$ of cases of blindness in type 1 diabetes were due to diabetic retinopathy but only 33\% in type 2 diabetics, with age-related cataract and open angle glaucoma commoner causes. ${ }^{15}$ This is supported by Rhatigan et al. in this issue of Eye: ${ }^{16}$ in only $27 \%$ of diabetic patients registered as blind or partially sighted in Tayside was the
Patricia M. Hart

Queen's University of Belfast

Directorate of

Ophthalmology

Royal Victoria Hospital Belfast BT12 6BA, Northern Ireland

Simon Harding

St Paul's Eye Unit

Royal Liverpool University

Hospital

Prescot Street

Liverpool L7 8XP, UK 
cause reported as diabetic retinopathy. Those with the poorest compliance were at highest risk. Ensuring good coverage of subgroups with greatest risk is difficult due to factors such as poor mobility or transport, and innovative solutions are required in this area.

Alternative outcome measures may be more helpful, such as numbers requiring vitreo-retinal surgery, numbers proceeding to laser, true positives detected, or numbers losing driving vision. It is prudent for those involved in screening to establish baseline population characteristics as a reference for future impact assessment. In this issue of Eye Broadbent et al. ${ }^{17}$ report baseline figures for their area with which to compare screening outcomes in future years.

The most appropriate method of introduction of a national screening initiative remains to be established, although certain requirements are clear. Implementation will probably be most achievable by local solutions tailored to available expertise and commitment with a nationally agreed set of minimum standards. Although only a consensus document the Exeter guidelines provide a very suitable starting point in stating, for example: screening programmes should reach a minimum sensitivity of $80 \%$, a specificity of $90 \%$ and screen a minimum of $1.5 \%$ of the local population. Reliable disease registers with call/recall facilities are essential. Less clear are the requirements for audit and quality control. A number of centres in the UK should be able to provide external quality control for photographic programmes but optometry-based systems will require a heavy commitment from local ophthalmologists to cover training, accreditation and validation. Sample size for annual audit will need to be large enough to allow meaningful sensitivity and specificity measurement and may require as many as 100 examinations per annum by an ophthalmologist who will also need to be externally validated. These quality control measures will be expensive but are essential if screening for diabetic eye disease is not to suffer the well-publicised problems that have beset the cervical screening programme over the last ten years.

\section{References}

1. British Multicentre Photocoagulation Trial. Proliferative diabetic retinopathy: treatment with xenon-arc photocoagulation. BMJ 1977;1:739-41.
2. Diabetic Retinopathy Study Research Group. Photocoagulation treatment of proliferative diabetic retinopathy. Ophthalmology 1981;88:583-600.

3. Early Treatment Diabetic Retinopathy Study Research Group. Photocoagulation for diabetic macular edema. Arch Ophthalmol 1985;103:1796-806.

4. Olk RJ. Modified grid argon (blue-green) laser photocoagulation for diffuse diabetic macular edema. Ophthalmology 1986;93:938-50.

5. British Multicentre Study Group. Photocoagulation for diabetic maculopathy: a randomised controlled clinical trial using the xenon arc. Diabetes 1983;32:1010-6.

6. Hercules BL, Gayed II, Lucas SB, Jeacock J. Peripheral retinal ablation in the treatment of proliferative diabetic retinopathy: a three-year interim report of a randomised, controlled study using the argon laser. Br J Ophthalmol 1977;61:555-63.

7. Evans J, Rooney C, Ashwood F, Dattani N, Wormald R. Blindness and partial sight in England and Wales: April 1990-March 1991. Health Trends 1996;28:5-12.

8. Bachman MO, Nelson SJ. Impact of diabetic retinopathy screening on a British district population: case detection and blindness in an evidence-based model. J Epidemiol Community Health 1998;52:45-52.

9. Rohan TE, Frost CD, Wald NJ. Prevention of blindness by screening for diabetic retinopathy: a quantitative assessment. BMJ 1989;299:1198-201.

10. Foulds W, McCuish A, Barrie T, et al. Diabetic retinopathy in the West of Scotland: its detection and prevalence, and costeffectiveness of a proposed screening programme. Health Bull 1983;41:318-26.

11. Javitt JC, Canner JK, Frank RG, Steinwachs DM, Sommer A. Detecting and treating retinopathy in patients with type 1 diabetes. Ophthalmology 1990;97:483-92.

12. WHO/IDF Europe. Diabetes care and research in Europe: the St Vincent Declaration. Diabet Med 1990;7:360.

13. Harding SP, Broadbent DM, Neoh C, White MC, Vora J. Sensitivity and specificity of photography and direct ophthalmoscopy in screening for sight threatening eye disease: the Liverpool diabetic eye study. BMJ 1995;311:1131-5.

14. Robinson R, Deutsch J, Jones HS, Fielder AR. Unrecognised and unregistered visual impairment. Br J Ophthalmol 1994;78:736-40.

15. Klein R, Klein BEK, Moss SE. Visual impairment in diabetes. Ophthalmology 1984;91:1-5.

16. Rhatigan MC, Leese GP, Ellis J, Ellingford A, Morris AD, Newton RW, Roxburgh STD. Blindness in patients with diabetes who have been screened for eye disease. Eye 1999;13:166-9.

17. Broadbent DM, Scott JA, Vora JP, Harding SP. Prevalence of diabetic eye disease in an inner city population: the Liverpool Diabetic Eye Study. Eye 1999;13:160-5. 